\title{
CLASSES SOCIAIS, CAMPO, GRUPOS: CONTRIBUIÇÕES PARA PENSAR A FUNÇÃO SOCIAL DA ESCOLA
}

\author{
SOCIAL CLASSES, FIELD, GROUPS: \\ CONTRIBUTIONS TO THINKING ABOUT THE SCHOOL'S SOCIAL ROLE
}

\section{CLASES SOCIALES, CAMPO, GRUPOS: \\ CONTRIBUCIONES PARA PENSAR EN LA FUNCIÓN SOCIAL DE LA ESCUELA}

\section{Rita de Cássia Pereira Lima Pedro Humberto Faria Campos ${ }^{2}$}

\begin{abstract}
RESUMO: Para abordar as relações sociais que ocorrem na escola, o presente artigo propõe ampliação da perspectiva econômica do conceito de "classes sociais", privilegiando a riqueza das interações sociais que ocorrem no cotidiano escolar, por causa, principalmente, da intensidade das trocas simbólicas presentes nesse espaço. Toma-se como referência o conceito bourdieusiano de "campo", em que circulam diversas formas de capital (econômico, cultural, social e simbólico) engendrando lutas materiais e simbólicas. O texto tem como ponto de partida concepções de "função social da escola" para diversos autores (Dewey, Durkheim, Parsons, Pistrak), chegando ao contexto francês dos anos 1970 em que Bourdieu defende a ideia da escola reprodutora da sociedade de classes, portanto, lugar de luta de classes. Essa discussão permite refletir sobre a inclusão/exclusão na escola, apontando-se a exclusão como "paradigma societário" dentro do qual há divisões sociais com dominantes e dominados, tanto economicamente quanto simbolicamente. Buscando um modo de compreender a função social da escola para além da dimensão econômica das classes e levando em conta a relação inclusão/exclusão, enfatizase um olhar simbólico para o espaço escolar com fundamentação na noção de "campo", com atenção para os “grupos". Defende-se a necessidade de buscar um referencial teórico que explique melhor as relações sociais entre diversos agentes/grupos, contexto social e cultura escolar. À guisa de conclusão, indica-se a fecundidade da aproximação entre a sociologia de Bourdieu e a perspectiva psicossocial da teoria moscoviciana das representações sociais para explicar as relações materiais e simbólicas que ocorrem na escola.
\end{abstract}

PAlAVRAS-CHAVE: Escola. Classe Social. Grupos. Pierre Bourdieu. Trocas Simbólicas.

ABSTRACT: To approach the social relations occurring in the school, this article proposes widening the economic perspective on the concept of "social classes", privileging the richness of social interactions occurring in school's everyday life, due mainly to the intensity of symbolic exchanges in this environment. As a reference, we adopted the Bourdieusian concept of "field", in which various forms of capital (economic, cultural, social, and symbolic) circulate, engendering material and symbolic struggles. The text starts with conceptions of the "social role of school" according to various authors (Dewey, Durkheim, Parsons, Pistrak) until the French context of the 1970 's, in which Bourdieu affirms the idea of schools as entities that reproduce the society of classes, therefore, a place of class struggles. This discussion allows reflecting about inclusion/exclusion in the school and pointing to exclusion as a "societarian paradigm" in which there are social divisions with dominant and dominated elements, both economically and symbolically. In pursuit of a way to understand the social role of school beyond the economic dimension of classes, and taking into account the inclusion-exclusion relationship, we emphasize a

\footnotetext{
${ }^{1}$ Doutorado em Ciências da Educação pelo Université Paris Descartes, França (1994). Professora da Universidade Estácio de Sá, São Paulo, SP. E-mail: ritalima@ netsite.com.br.

${ }^{2}$ Doutorado em Psicologia pelo Université de Provence, França (1998). Professor Adjunto da Universidade do Estado do Rio de Janeiro. E-mail: pedrohumbertosbp@ terra.com.br.
}

Recebido em: 05/07/2015 - Aprovado em: 16/11/2015. 
symbolic perspective to the school environment founded on the notion of "field", with attention to "groups". We affirm the necessity of seeking a theoretical framework that can better explain the social relations between various agents/groups, social context, and school culture. By way of conclusion, we point to the fruitfulness of approximating Bourdieu's sociology to the psychosocial perspective of Moscovici's theory of social representations in order to explain the material and symbolic relations occurring in the school.

KEYWORDS: School. Social Class. Groups. Pierre Bourdieu. Symbolic Exchanges.

RESUMEN: Para tratar de las relaciones sociales que ocurren en la escuela, el presente artículo propone ampliar la perspectiva económica del concepto de "clases sociales", privilegiando la riqueza de las interacciones sociales que tienen lugar en el día a día escolar, a causa, principalmente, de la intensidad de intercambios simbólicos presentes en este espacio. Se toma como referencia el concepto bourdieusiano de "campo", en el que circulan diversas formas de capital (económico, cultural, social y simbólico) que originan luchas materiales y simbólicas. El texto tiene como punto de partida concepciones de "función social de la escuela" de diferentes autores (Dewey, Durkheim, Parsons, Pistrak) para llegar al contexto francés de los años 1970, en el que Bourdieu defiende la idea de la escuela reproductora de la sociedad de clases; por tanto, lugar de lucha de clases. Esta discusión permite reflexionar acerca de la inclusión/exclusión en la escuela y distinguir la exclusión como "paradigma societario" que comprende divisiones sociales con dominantes y dominados, tanto económicamente como simbólicamente. Buscando un modo de entender la función social de la escuela más allá de la dimensión económica de las clases y teniendo en cuenta la relación inclusión-exclusión, se enfatiza una mirada simbólica hacia el espacio escolar con fundamentación en la noción de "campo", con atención a los "grupos". Se defiende la necesidad de buscar un referente teórico que explique mejor las relaciones sociales entre diversos agentes/grupos, contexto social y cultura escolar. A modo de conclusión, se indica la fecundidad de la aproximación entre la sociología de Bourdieu y la perspectiva psicosocial de la teoría moscoviciana de las representaciones sociales para explicar las relaciones materiales y simbólicas que ocurren en la escuela.

PALABRAS CLAVE: Escuela. Clase Social. Grupos. Pierre Bourdieu. Intercambios Simbólicos.

\section{INTRODUÇÃO}

A escola atual, que por lei deve acolher a diversidade e ser inclusiva (BRASIL, 2014), demanda redimensionamentos no espaço escolar, sobretudo nos aspectos materiais e simbólicos das relações sociais. A “escola para todos”, como já mencionou Macedo (2005), parece estar em construção e exige mudanças tanto estruturais quanto no pensamento de pessoas e grupos vinculados a instâncias políticas e educacionais. A desejada "inclusão", frequentemente pensada com sua antítese, a "exclusão", vem no bojo dessa "escola para todos" e constitui uma condição propícia para pensar a questão das "classes sociais" e das desigualdades.

Ao estudarem a instituição escolar, Bourdieu e Passeron (1970) privilegiaram as relações entre o sistema de ensino e a estrutura das relações entre classes sociais. Os autores apresentam a escola como reprodutora da estrutura social porque ela reforça privilégios das classes sociais dominantes, portanto mais favorecidas para obterem o sucesso escolar. Eles mostram a função perversa do sistema escolar que, embora obrigatório e acessível a todos, exclui alunos das classes desfavorecidas em razão da reprodução de privilégios culturais que dissimulam relações de força, com fortalecimento do domínio da "classe dominante" sobre a "classe dominada". Sendo assim, o sistema de ensino e a ação pedagógica impõem a cultura da "classe dominante" como verdade universal. As relações sociais se tornam, portanto, relações de concorrência entre "arbitrários culturais" dominantes e dominados, sendo função da escola 
reproduzir o "arbitrário cultural dominante". São essas relações de força entre classes sociais que sustentam o poder arbitrário que impõe um determinado arbitrário cultural, o qual vai reproduzindo tais relações entre as classes.

De acordo com Nogueira e Nogueira (2002), as ideias de Bourdieu sobre a escola reprodutora das desigualdades sociais mostram que a instituição escolar perde seu papel como instância transformadora e democratizadora da sociedade, passando a legitimar os privilégios sociais. Para os autores, na perspectiva bourdieusiana a escola exerce funções de reprodução e de legitimação das desigualdades sociais por ser reconhecida como legítima, portadora de discurso não arbitrário, socialmente neutro. Eles defendem que o "argumento central do sociólogo é, então, o de que ao dissimular que sua cultura é a cultura das classes dominantes, a escola dissimula igualmente os efeitos que isso tem para o sucesso escolar das classes dominantes" (p. 30). Exigindo uma relação específica com a cultura e com o saber, a escola acaba privilegiando os filhos das classes dominantes, reproduzindo assim a estrutura social e perpetuando a dominação social. Porém, segundo os autores, a análise macrossociológica de Bourdieu não necessariamente se compatibiliza com planos microssociológicos. Nogueira e Nogueira (2002, p. 34) afirmam: "Existem diferenças significativas no modo como cada escola e ou professor participa desse processo de reprodução social. Essas diferenças foram, em grande medida, negligenciadas por Bourdieu".

Um aspecto marca o amplo e longo debate provocado pela Reprodução (BOURDIEU e PASSERON, 1970): tanto defensores, quanto detratores das ideias de Bourdieu e Passeron, pautavam suas posições em uma visão de dominação amparada em uma concepção monolítica e "econômica" das classes sociais. Nessa época, nem a noção de campo, nem de agente (e não de classe) estavam amadurecidas no pensamento dos autores.

Esse pensamento de Bourdieu da década de 1970 foi mudando com o tempo. Naquela época, a preocupação do autor era o problema da reprodução da estrutura social, com valorização do sistema de condições objetivas que operam na instituição escolar. O ponto central da teoria do sistema de ensino elaborada por ele era o conjunto das relações entre instituição escolar e estrutura das relações entre as classes sociais, privilegiando a reprodução das condições objetivas. Posteriormente, por exemplo, em "La noblesse d'Etat" (BOURDIEU, 1989), além das estruturas sociais que organizam a instituição escolar, o autor também passou a considerar as estruturas mentais que organizam o julgamento dos professores, levando em conta possibilidades de criação (por meio de elementos simbólicos) e não somente de reprodução. O autor passa a admitir que a escola também funciona como uma máquina cognitiva que produz classificações, escapando de uma visão estritamente estruturalista.

Com o tempo Bourdieu passou defender mais que são condições materiais e simbólicas que constroem o espaço social, consequentemente o espaço da escola. Ao se referir à sua relação com a obra de Marx, especificamente no que se refere às classes sociais, Bourdieu (2004, p. 66) afirma: "Não há dúvida de que, se nós falamos de classe, é essencialmente graças a Marx. E poderíamos mesmo dizer que, se há algo na realidade semelhante a classe, é em 
grande parte graças a Marx, ou, mais exatamente, ao efeito de teoria exercido pela obra de Marx". Porém, o autor declara que não se sente satisfeito com a "teoria das classes" de Marx, alegando que desejou "romper com a visão realista que as pessoas comumente têm delas e que leva a questões do gênero: os intelectuais são burgueses ou pequenos burgueses? Isto é, questões de limite, de fronteira, questões que em geral são resolvidas por atos jurídicos" (p. 66). O autor afirma:

Meu trabalho consistiu em dizer que as pessoas estão situadas num espaço social, que elas não estão num lugar qualquer, isto é, intercambiáveis, como pretendem aqueles que negam a existência das "classes sociais", e que, em função da posição que elas ocupam nesse espaço muito complexo, pode-se compreender a lógica de suas práticas e determinar, entre outras coisas, como elas vão classificar e se classificar, e, se for o caso, se pensar como membros de uma "classe". (BOURDIEU, 2004, p. 67).

Dentro dessa perspectiva, as estruturas sociais que estão na base da "teoria dos campos" de Bourdieu (às vezes associada a "grupos" ou "classes sociais") são dotadas de sistemas materiais e simbólicos. Assim, um determinado "campo" não é operado somente pelo "capital econômico", constituído por fatores de produção como indústria, terra, trabalho, moeda, bens econômicos e rendas, e por interesses econômicos, envolvendo lucro, acumulação e processos de concentração de capital econômico e provocando a "luta de classes". Bourdieu (1979, 1994) afirma que o campo social de lutas é também formado por outros tipos de capital, além do econômico: o cultural, o social e o simbólico. O capital cultural seria originalmente relacionado às desigualdades de desempenho escolar entre crianças de classes sociais diferentes, com acesso desigual a bens culturais (como bibliotecas, viagens, artes de maneira geral). O capital social estaria relacionado aos recursos que garantem uma rede durável de relações sociais (como frequentar clubes e práticas esportivas). E o capital simbólico refere-se ao conhecimento e ao reconhecimento, nascendo da relação entre uma forma de capital (econômico, cultural, social), o gênero, e os agentes socializados que o conhecem/reconhecem e lhe dão valor.

Com base nessas reflexões, o presente artigo se propõe a pensar a questão das "classes sociais" para além da dimensão econômica, buscando apoio nas noções de campo/grupos desenvolvidas por Bourdieu. Pretende-se, dessa maneira, contribuir com um novo olhar para pensar a função social da escola. Considerando o universo escolar marcado pela presença de diversidades humanas que, nos planos material e simbólico, podem provocar divisões, relações de poder, exclusões, apresenta-se aqui uma perspectiva teórica para a abordagem da instituição escolar que articula três aspectos: a) concepções de "função social da escola" por alguns teóricos (Dewey, Durkheim, Parsons, Pistrak, entre outros), chegando ao contexto francês dos anos 1970 em que Bourdieu defende a ideia da escola reprodutora da sociedade de classes, o que permite uma discussão sobre a questão da inclusão/exclusão na escola; b) a exclusão social como paradigma societário e sua relação com divisões sociais na escola; c) as concepções de "campo" e de "grupo" em Bourdieu, como alternativa para avançar a concepção econômica de classes sociais no contexto escolar. Na continuidade dessas reflexões, o texto procura indicar a fecundidade da aproximação entre a sociologia de Bourdieu e a teoria moscovicina das representações sociais para a compreensão das relações sociais que ocorrem na escola. 


\section{A REPRODUÇÃO SOCIAL DA DESIGUALDADE E A FUNÇÃO SOCIAL DA ESCOLA}

Com aproximadamente meio século de diferença, Dewey $(1959,1965)$ apresentou visão totalmente distinta da função social da escola, vista como o sítio próprio à formação do indivíduo para a democracia. Enquanto Boudieu e Passeron (1970) realizam pesquisas empíricas de base sociológica e chegam a uma avaliação, Dewey, situado na fronteira entre uma filosofia da educação nascente como campo e uma psicologia pragmática, propõe princípios pedagógicos para a organização e o funcionamento da escola. Os primeiros constatam que, ao final das contas, a escola tal qual captada por seus instrumentos, finda por ser uma máquina para a reprodução do status quo. Já o segundo autor vai tecer seus argumentos para sustentar a visão de que a escola deve trabalhar para a produção de um tipo específico de sociedade, formando cidadãos moralmente consistentes e livres, uma vez que a escola forma para uma sociedade igualitária, organizada na forma da democracia.

Retomando o pensamento de Durkheim (2004, p. 11), a escola é uma instituição moderna, ou para além, é um fato social, ou seja, está inscrita na classe de fenômenos que compreendem "toda maneira de agir fixa ou não, suscetível de exercer sobre o indivíduo uma coerção exterior; ou então ainda, que é geral na extensão de uma sociedade dada, apresentando uma existência própria independente das manifestações individuais que possa ter". Assim, como tal, a escola se impõe coercitivamente ao indivíduo que, para seu próprio bem, sofrerá a sua ação educativa integrando-se e solidarizando-se com o sistema social em que vive.

A sociedade, para Durkheim (2004), é um conjunto de normas de ação, pensamentos e sentimentos que não existem apenas nas consciências dos indivíduos, mas que são construídas exteriormente e se apresentam como um imenso corpo social, no qual cada instituição tem sua função específica. A função social da escola é, principalmente, a formação moral dos indivíduos. A moral da sociedade se estabelece a partir do momento em que seus cidadãos compartilham valores formando uma consciência coletiva, fundada tanto na coesão, quanto na solidariedade. O desenvolvimento moral do indivíduo e sua integração em um princípio de coesão social dependem da socialização, vivida na família e na escola. E esta última teria um papel determinante no aprendizado das formas complexas da divisão social do trabalho em sociedades altamente diferenciadas, como as sociedades modernas.

Dias (1990) destaca criticamente dois aspectos no funcionalismo de Durkheim: o da homogeneidade (fixando de antemão, na alma da criança certas similitudes essenciais) e o da diversidade dos meios sociais (profissões, classes, grupos) especialmente os grupos profissionais. A escola não pode ser a escola de igualdade de chances. Ela deve promover talentos de cada um e formar uma elite cultural legítima. A Sociologia Funcionalista de Durkheim também é criticada por Meksenas (2011), porque o autor acreditava em uma ordem social "ideal" e afirmava que o importante era buscar a ordem das coisas. Pode-se pensar que Durkheim supunha que o acesso à escola pública e gratuita daria igualdade de oportunidade a todos; a escola seria então um lugar privilegiado para o desenvolvimento dos diferentes dons 
de cada indivíduo, independentemente de sua origem de "classe". A escola seria, nessa perspectiva, uma instituição neutra que difundiria o conhecimento racional e objetivo, e que selecionaria seus alunos com base em critérios racionais.

Parsons (1974), sociólogo norte-americano divulgador da obra de Durkheim nos Estados Unidos da América (EUA), discorda de Durkheim quanto à socialização dever ser coercitiva. $\mathrm{O}$ autor afirma que esta é necessária como complementação do sistema social e do sistema de personalidade, pois ambos têm necessidades básicas. Trata-se de um processo que se desenvolve por meio de mediações primárias. A criança aceita o marco normativo do sistema social em troca de amor e carinho. Os pais iniciam o processo de socialização primária. A criança não percebe que as necessidades do sistema social estão se tornando suas próprias necessidades. Para Parsons, o indivíduo é funcional para o sistema social e os princípios básicos que fundamentam esse sistema são: continuidade, conservação, ordem, harmonia, equilíbrio. O sentido da formalização de socialização parsoniano leva à aprendizagem de papéis sociais.

Outro exemplo de visão da instituição escolar encontra-se na concepção de Pistrak (1981), um dos grandes pedagogos soviéticos, para quem a função social da escola também seria a de formação da própria sociedade, por intermédio da formação de um tipo específico de homem. Só que, neste, a referência não é a democracia no modelo capitalista, mas o socialismo, e seu ideal não é o "cidadão moralmente consciente", mas o "homem polivalente". O autor afirmava não existir prática revolucionária sem teoria pedagógica revolucionária e sua visão educacional coincidiu com o período de ascensão das massas na Revolução Russa que, desde os primeiros dias, concebeu a escola socialista como única. Ele defendia que a pedagogia deveria formar cidadãos ativos e participantes da vida social, desalienados vinculados ao presente, superando o egoísmo e o individualismo. Assim, a escola ensinaria mais com atitudes e comportamentos práticos. Todas as crianças deveriam passar pelo mesmo tipo de educação, com direitos iguais e preferência pelos mais pobres. Se em Durkheim e em Dewey pode-se enxergar uma escola isenta da luta de classes, em Pistrak encontra-se um projeto de superação da própria sociedade de classes.

O legado de Dewey para a educação é extremamente importante como fundamento de uma visão de educação enraizada na democracia, na qual a escola é um "microcosmos" da sociedade, um "embrião" da democracia. Para o autor, a escola deveria assumir um papel participativo na transformação para uma melhor ordem social. É partir das ocupações (práticas sociais) que a criança irá se iniciar no desenvolvimento moral e social. A sala de aula deveria ser um espaço de vida comunitária democrática, voltada para a dignidade humana e para a inteligência científica pensada fora da escola.

A partir dos anos 1960, emergem sociologias e pedagogias ditas "críticas", cujo espectro é de pessimismo quanto à função social da escola. A instituição escolar é vista como reprodutora, porque fornece às diferentes classes e grupos sociais, formas de conhecimento, 
habilidades e cultura que não somente legitimam a cultura dominante, mas também direcionam os alunos para postos diferenciados na força do trabalho (ESTABLET; BAUDELOT, 1971; GIROUX, 1988). Establet e Baudelot (1971) são teóricos de base marxista que afirmam, por exemplo, que o processo educativo que acontece na escola é desigual, pois esta é controlada pela classe dominante; nesse sentido, a escola é a instituição mais eficiente para segregar as pessoas, dividir, marginalizar, com o objetivo de reproduzir a sociedade de classes. Esses autores apresentam o que pode se chamar de primeira "teoria da escola dualista", pois visavam mostrar que existiam duas redes diferentes de escolas: uma para as elites e outra para o proletariado.

Outros autores (BARRÈRE; SEMBEL, 2006; SNYDERS, 2005) vão destacar, dentro de um cenário também dito "crítico", que o processo de transmissão da ideologia na escola não ocorre sem conflito, sendo a instituição escolar um "espaço de contradição". No seu interior existem forças progressistas atuando para a transformação como: resistência dos alunos, professores progressistas, pressão de movimentos populares. A escola é o local de luta para a transformação social porque o poder fazer é sempre o poder social. Em sentido mais amplo, a escola é lugar da luta de classes.

Em Bourdieu e Passeron (1970), encontra-se uma visão em que o estrato social ao qual pertence a família intervém no êxito e na orientação escolar dos filhos, por meio de fatores concretos como a atmosfera intelectual da família, a estrutura da língua falada, o acesso a bens culturais, atitude desenvolvida em relação à escola. A educação perde o papel que lhe fora atribuído de instância transformadora e democratizadora das sociedades e passa a ser vista como uma das principais instituições por meio das quais se mantém privilégios e se legitimam privilégios sociais. A teoria de socialização escolar de Bourdieu e Passeron (1970) mostra que a função da escola é a de assegurar o ajustamento entre as origens sociais e os destinos sociais estatisticamente previsíveis dos indivíduos. Desse modo, a escola não é neutra, não é justa, não promove a igualdade de oportunidade e reflete a cultura da classe dominante. De acordo com Barrère e Sembel (2006), a escola não faz senão reconhecer os seus, aqueles que já estão de antemão socialmente destinados a serem reconhecidos por ela, identificados por seus habitus de classe.

Dubet (2003) afirmou que todo sociólogo passa pela teoria da reprodução e se confronta a ela; pois não há realmente outra que seja, ao mesmo tempo, uma teoria da escola, uma teoria da mobilidade social, uma teoria da sociedade e uma teoria da ação. O autor ressalta que a crença na objetividade da cultura escolar e no papel libertador da escola não passa de uma ficção necessária à realização de seu papel de reprodutora de desigualdades. São as desigualdades sociais que comandam diretamente o acesso às diversas formas de ensino. Uma das consequências desse sistema é que a escola aparece justa e "neutra" no seu funcionamento, enquanto as injustiças e as desigualdades sociais é que são, diretamente, a causa das desigualdades escolares. Segundo o autor, quanto mais a escola intensifica o seu raio de ação, mais ela exclui, apesar das políticas que visam atenuar esse fenômeno. Nesse contexto, a 
exclusão não é apenas uma categoria do sistema e dos processos globais. Ela é também uma das dimensões da experiência escolar dos alunos.

Um novo cenário de análises se desenha, particularmente inspirado pelo desenvolvimento dos conceitos bourdieusianos (habitus, campo, dominação simbólica e trajetórias, dentre outros): desigualdade social, escola e exclusão serão doravante temas integrados. Se a lógica da Reprodução causou impacto pela "demonstração" da reprodução das desigualdades, uma profunda novidade não gozou do mesmo sucesso no mundo acadêmico: a noção de dominação simbólica (ainda pouco desenvolvida, face à inexistência naquele momento do conceito de "capital simbólico" e da "economia das trocas simbólicas"). Na mesma direção de Gramsci (1989), Bourdieu ressalta o peso da dimensão cultural na reprodução ou na transformação social.

As críticas dirigidas à escola, nos anos 1960 e 1970, portavam a acusação da escola reprodutora de desigualdades. A rigor, o tema da desigualdade social se refere à distância entre ricos e pobres ou, com maior precisão, pode-se dizer que se refere à posição que o indivíduo ocupa na divisão social do trabalho e ao acesso, ou não, à riqueza e ao consumo. Contudo, para além da reprodução do status quo sedimentado ao longo dos anos de escolarização, essas críticas apontavam também, algumas de modo mais visível, outras mais implícitas, para a escola como instituição que forma os mecanismos de comparação, de categorização e de discriminação social; a escola forma as competências cognitivas e sociais que estão na base dos processos de percepção, de julgamento e de atribuição de valor às categorias sociais. Desse modo, as críticas à reprodução da desigualdade entre as classes sociais pela escola já apontavam para uma visão desta instituição como, não somente participante, mas principal instância da gênese dos mecanismos simbólicos que fundam a desigualdade e a exclusão. A escola é a instituição que ensina o indivíduo a se ver como produto de uma trajetória, de um percurso, de tal modo que, ao nos percebermos como membros desta ou daquela categoria social (homens/mulheres, pobres/ricos/, cristão/mulçumano/judeu) ela fornece os elementos cognitivos (simbólicos) para que cada um, não somente se veja como pertencente a um estrato, como também responsável por essa vinculação, uma vez que é fruto de um percurso individual.

Não se trata mais de processos e atos de coerção no sentido pleno, mas de submissão (simbólica) voluntariamente consentida. Mesmo quando a instituição escolar se afirma como inclusiva, ou seja, quando emergem e se instalam modelos educacionais autoproclamados "inclusivos", a escola pode acabar por operar e formatar competências e processos que dinamizam a exclusão (Libâneo, 2000). Uma mudança de eixo dos debates entre a desigualdade (e a "dominação" que assegura sua reprodução) e a exclusão, solicita um exame mais apropriado da noção mesma de "exclusão", buscando evitar a fetichização do termo. 


\section{A ESCOLA E A EXCLUSÃO SOCIAL COMO PARADIGMA SOCIETÁRIO}

A naturalização do termo exclusão social é de tal monta que muitos profissionais e pesquisadores da área de educação não se interrogam por qual razão ele não existia nas análises no campo das ciências sociais há aproximadamente 40 anos atrás. Pode-se situar o aparecimento, ou a visibilidade da expressão "exclusão social", a partir dos anos 1970 na Europa, particularmente no debate político na França (LENOIR, 1974), destacando-se o aspecto da falta de dignidade humana na condição a qual estavam submetidos alguns segmentos (os "sens papiers", ou seja "sem documentos"). A exclusão social se tornou, mais que um tema ideal (SASSIER, 1990), um objeto midiático nas últimas décadas do século XX. Porém, a expressão estava e está amalgamada à discussão sobre a desigualdade social. No senso comum, a figura do excluído não pode ser totalmente distinta da figura social do pobre; no discurso midiático, os dois termos, pobre e excluído, passam a ser intercambiáveis, com uma diferença: o segundo não se encontra marcado negativamente, enquanto o primeiro leva necessariamente a uma "desqualificação social".

O grande mérito da noção de exclusão está no fato de que ela desloca o eixo das atenções para com a "pobreza" e os marginalizados, do determinismo econômico para fatores políticos, sociais e simbólicos. A noção de exclusão causa um grande impacto, não somente nas ciências sociais, mas, sobretudo, no seio da sociedade, porque sendo vaga e polissêmica, permite um "repensar" da situação dos pobres e dos "excluídos". Para Martins (1997), a "novidade" introduzida pelo conceito de exclusão é que ele nos mostra, dentro do "velho" fenômeno (a pobreza, a desigualdade, a exploração), coisas novas que não conhecíamos e que não éramos capazes de ver; para esse autor, a palavra exclusão está desmistificando a palavra pobre. O problema das sociedades atuais não pode ser definido em termos de possuir ou não os bens materiais, de acesso ou não ao mercado de trabalho, mas em termos de inclusão.

Alguns autores denunciam o uso mecânico da noção de exclusão (PAUGAM, 1996; MARTINS, 1997), cuja consequência é esconder a visão da pobreza como fenômeno político e do conflito, como se as populações vítimas da chamada exclusão estivessem totalmente "à parte" ("apartadas") da sociedade. Na realidade, elas continuam, de algum modo ("marginal", precário e instável), exercendo "de dentro" uma resistência. Martins (1997) afirma que a rigor "não existe exclusão", UMA exclusão como processo monolítico, fundado em um critério ou procedimento único (por exemplo, a posição do indivíduo na divisão social do trabalho). Para esse autor, o que existe é contradição, e existem vítimas de processos sociais, políticos e econômicos excludentes. A ideia de processos ou dinâmicas sociais também é consolidada por outros autores como Castel (1996), que fala de procedimentos ritualizados e coordenados de exclusão, ou Paugam (1996), que afirma a existência de processos excludentes convergentes. Nesse sentido, a crítica de Martins ao uso equivocado do conceito de exclusão torna-se não somente compreensível, mas também bastante coerente: não existe "exclusão", o que existe são formas precárias, instáveis e marginais de inclusão. 
O uso da expressão "exclusão social" deveria ser restritamente aplicado frente às situações nas quais o sujeito está imerso em um quadro geral de perdas e de processos ritualizados que sancionam um movimento de "deixar ou colocar para fora", situações de uma "exclusão geral", correspondendo à figura do miserável, do indivíduo "sem utilidade social" ou daquele que "não pertence a este tecido social". Constituído como excluído, e não como pobre, o olhar (das políticas públicas, da caridade ou das ciências) destaca ainda e para além dos aspectos materiais da pobreza, os aspectos simbólicos e interacionais: o sofrimento, as ações de resistência ou acomodação, as estratégias para fazer face aos procedimentos ritualizados de exclusão. Embora a noção permaneça polissêmica e nenhum ator social (políticos, governos, cientistas) possam controlar o desenvolvimento semiótico da palavra, as concepções de exclusão reconhecidas até então têm em comum apontar para uma ruptura ou fragilidade do vínculo social. Enfim, discutir a exclusão social do pobre significa inscrever esta discussão nas dinâmicas sociais, observar as relações específicas entre os diferentes atores, aceitar o caráter político deste debate e restituir o lugar de sujeito.

Em síntese, para além das concepções econômicas da exclusão (GAZIER, 1996; FASSIN, 1996), ou daquelas chamadas "sociológicas" (DONZELOT, 1991; DELARUE, 1991; PAUGAM, 1996), que dão ênfase também à dimensão política envolvida nestes processos sociais; para se ascender ao nível de análise das interações cotidianas que operacionalizam a exclusão, é necessário que as teorias possam dar conta da dimensão simbólica; isto se fez necessidade analítica a partir do momento em que a exclusão social se tornou um paradigma societário.

Um paradigma societário é um conjunto de representações de ordem social, suficientemente concordantes e estabilizadas no tempo, as quais organizam, na perspectiva do conjunto de uma dada sociedade, uma reflexão sobe os fundamentos e os modos de regulação desta mesma sociedade. Dito de outro modo, na prática, na vida social, não há agente ou ator influente na esfera pública atualmente que não seja chamado, às vezes exigido, a se posicionar face à exclusão ou à situação de um grupo de "excluídos". Não há, na esfera pública, agente que não realize uma reflexão sobre seu lugar e sobre os fundamentos da organização social sob o impacto do contato ou da exposição de situações de exclusão.

Atribuir a condição de "excluído" a alguém, ou a um grupo, é da ordem do reconhecimento de um mérito (merece ser reinserido), de uma necessidade, de uma fragilidade, de uma injustiça ou de uma incapacidade. Uma vez tornada paradigma, a exclusão torna-se também representação social e se descola dos seus contextos específicos de origem, de tal modo que se consolidou o uso "incompleto" e passou-se a designar situações de discriminação social como relevando da "exclusão", deixando elíptico o complemento "social", de tal modo que passam a ser identificados "excluídos" que não são pobres.

A exclusão social não é uma característica própria do sujeito dito "excluído"; ela é um atributo recebido de fora para dentro. De fato, é um valor atribuído a alguém e é também um fato de linguagem, sem dúvida uma formação simbólica da cultura. Distinta da pobreza, como 
dimensão material, ou da marginalização social resultante direta da divisão social do trabalho (e o tipo de inserção com o mercado de trabalho), a noção de exclusão social inscreve o debate e o discurso sobre o sujeito e as desigualdades na ordem do simbólico. Pode-se perguntar, por exemplo, quais seriam os "processos ritualizados de exclusão" no caso de crianças portadoras da síndrome do autismo, quando estão fora da escola e quando estão dentro dela? A situação da criança obesa dentro da escola é de discriminação ou de "exclusão"? O aluno deficiente visual encontra-se frente aos mesmos processos de exclusão que outro com síndrome de Down?

Não é tarefa simples balizar as relações entre desigualdade e exclusão. Uma das dificuldades encontra-se no fato de que a noção de desigualdade solicita dois termos a serem comparados e na história das sociedades industriais esta visão do conflito se inscreveu em uma divisão binária (sem dúvida ideológica), cuja força do apelo é sua base material e sua visibilidade, a diferença entre ricos e pobres. $\mathrm{O}$ desafio conceitual se situava no fato de que "ricos" e "pobres", não são classes sociais no sentido teórico. O avanço e complexificação do assalariado a partir dos anos 1930 (SASSIER, 1997) tornou anacrônica qualquer tentativa de assimilação mecânica entre trabalhador e pobre. E no sentido teórico, a superação de uma visão binária do conflito social, entre burguesia e proletariado, já se encontra, ainda que pouco desenvolvida, em textos marxianos (LOSURDO, 2015).

Assim, a crítica da escola como reprodutora de desigualdades sociais não é anulada, mas ampliada em face de novas interrogações decorrentes do paradigma da exclusão. Pode-se pensar na "função social da escola" em termos de produzir, sancionar e legitimar procedimentos ritualizados e coordenados de exclusão, entre os quais estariam os esquemas cognitivos de percepção e julgamento das categorias sociais, esquemas que produzem a desqualificação social de uns em benefício de outros?

$\mathrm{Na}$ perspectiva de compreender a função social da escola para além da dimensão econômica das classes sociais e de pensar a relação inclusão/exclusão escolar dentro de um paradigma societário, propõe-se o olhar para o simbólico com base nas noções de "campo" de Pierre Bourdieu e eventualmente quando o autor se refere a "grupos".

\section{CAMPO E GRUPO EM BOURDIEU: (RE) PENSANDO A CONCEPÇÃO ECONÔMICA DE CLASSES}

Pode-se considerar que Bourdieu é um pensador-sociólogo cujas ideias singulares foram objeto de longas e complexas polêmicas, ora sendo atribuída a ele uma posição de ferrenho crítico do pensamento marxista, ora sendo atribuída uma "adoção exagerada" ao marxismo (particularmente contra um estruturalismo campeante nas ciências sociais, na Europa, entre os anos de 1950 e 1970). Não nos parece abusivo afirmar que Bourdieu se inscreve (ativamente) em um debate contra o estruturalismo, com Marx e contra Marx, sob três pontos cruciais.

O primeiro, debatendo a visão marxiana da luta de classes como uma teoria geral do 
conflito social, mesmo na versão pouco desenvolvida das "lutas de classes", no plural, que aparece no Manifesto (MARX; ENGELS, 1998). Essa visão tem implicações profundas, dado sua consequência incontornável: todo conflito que realmente conta na mudança da sociedade seria, no fundo ou na base, luta de classes? Esta perspectiva solicita que sejam enfrentadas questões com as quais Marx não se deparou, ou não examinou completamente: a homofobia, os conflitos interétnicos, a segregação dos doentes mentais ou os alunos portadores de síndrome do espectro autista. Nesses conflitos, a divisão social do trabalho e a posição ocupada pelo sujeito social explica a natureza dos conflitos e é suficiente para abarcar os fatores determinantes do conflito? Desigualdade e dominação seriam ferramentas conceituais suficientes? Neste caso, a noção de exclusão dos alunos com "necessidades especiais" é somente acessória ou promove um efeito de escamoteamento do verdadeiro conflito?

É sabido que no pensamento marxiano há espaço para o se chamou de "lutas emancipatórias" (MARX, 1986; MARX; ENGELS, 1998). Ao menos três ordens de lutas receberam atenção de Marx: a) do proletário em relação à burguesia, nas metrópoles industrializadas do século XIX; b) dos povos, com a escravatura dos negros em primeiro plano, e das nações colonizadas ou semicolonizadas; c) das mulheres, face à exploração doméstica. Ele opera assim uma comparação de equivalência entre a escravidão do "povo negro" no continente americano (com ênfase na análise da guerra de secessão nos EUA), a "escravidão das nações colonizadas" e seus povos, a "escravidão doméstica", sofrida pela mulher e a “escravidão moderna”, ou seja, salarial. A dominação, a coerção e a exploração são colocadas por Marx não somente no plano "econômico", mas também histórico e "político"; demonstrando de modo inequívoco que lutas vistas (sobretudo por pensadores liberais de seu tempo) como exclusivamente nacionais ou étnicas, tinham como fundamento histórico elementos estruturais vinculados à divisão social do trabalho; ou seja, as lutas emancipatórias sempre estiveram vinculadas à "luta de classes", no plural.

Marx reconhecia a diversidade das formas de luta, porém não analisou ou forneceu ferramentas conceituais para analisar a especificidade dessas lutas, vinculando a diversidade a uma dimensão "política”. A ordem do político se apresenta em Marx com análise histórica dos eventos e ações dos agentes, com foco nas relações e efeitos de poder. Ele reconhecia o papel da religião nas lutas emancipatórias nacionalistas na Polônia ou na Irlanda, por exemplo. Contudo, não analisou como, por quais processos e mecanismos, lutas, conflitos, se formou uma identidade nacional, em que um dos elementos sustentadores, nos casos estudados, foi a religião. Sem essa crença coletiva, tais lutas, tal qual analisadas do ponto de vista estrutural por Marx, se realizariam? Se a exploração do proletário, sua "escravidão" é comparável à exploração e escravidão da condição doméstica feminina, sob que parâmetros, quais critérios, quais dimensões, a "classe proletária" seria comparável a uma "classe feminina"? Se a posição ocupada na divisão social do trabalho fosse suficiente, neste caso não se estaria privilegiando uma "visão de classes" insuficiente? No caso específico da condição feminina, Bourdieu (2012) pode propor, quase no final de sua vida, sua visão articulada acerca da dominação masculina, incluindo o gênero como um dos princípios de distribuição das posições dos agentes (de classe, 
frações de classe, grupos e indivíduos) nos campos.

Um segundo ponto de debate se articula na órbita das múltiplas respostas possíveis (inclusive entre marxistas de diversas nuances) à questão: a luta de classes, em Marx, tem por fundamento último a posição do indivíduo na divisão social do trabalho? Neste cenário, a proposição das formas do capital de Bourdieu (econômico, social, cultural, simbólico e gênero) não pode ser subsumida a uma visão do próprio capital marxiano como relação social totalitária (ou seja, uma visão da mercadoria como princípio de todas as determinações). Ao colocar o capital como efeito simbólico das outras formas de capital e do gênero, produzindo seus efeitos de reconhecimento e não reconhecimento, Bourdieu (1979, 1989, 2004, 2012) estabelece análises que constituem uma ruptura ("com" e "contra") Marx. Mais ainda, o sociólogo francês recoloca a necessidade de análises da ordem do simbólico e seus efeitos de signo, no primeiro plano do campo de lutas, não independente das outras formas de capital, mas também não como efeito secundário desses.

O terceiro ponto decorre do debate engendrado em torno das respostas possíveis à questão que organiza o segundo ponto e concerne justamente a diferença entre os conceitos de dominação, hegemonia e dominação simbólica, postulada no amadurecimento do pensamento de Bourdieu, portanto, bem depois da publicação de a Reprodução.

No debate de Bourdieu com Marx e marxistas de seu tempo (BURAWOY, 2011), emerge a articulação entre desigualdade social, dominação e exclusão. De um lado, a reprodução das desigualdades sociais é um mecanismo da dominação de classe; de outro, se concordamos com uma concepção da exclusão social como conjunto de fenômenos (ou efeitos no real) que integra, mas não se resume à desigualdade de classes (cujo ethos é a luta de classes em suas dimensões econômica, política e histórica), ela se articula com a dominação simbólica, uma vez que revela e recoloca no centro do campo social os elementos simbólicos, para além e para aquém da divisão social do trabalho. Parece-nos insuficiente, por exemplo, pensar na libertação das mulheres de sua "escravidão doméstica" sem analisar a diferença biológica entre os sexos e os séculos de significados culturais que foram produzidos e reconstruídos ao longo da história das sociedades; e os efeitos de signo dessas significações culturais, nas relações de poder, ou seja em uma perspectiva de poder simbólico. Quando Marx e Engels (1986) afirmam que "para o Burguês, a mulher nada mais é que um instrumento de produção", dão a entender que a escravidão doméstica está vinculada à posição na divisão social do trabalho; no entanto, uma verdade mais completa seria aquela na qual "o proletário também pode ver na mulher um instrumento de produção".

Do mesmo modo, Marx considerava a guerra de secessão americana, cujo resultado foi o fim da escravatura naquele país, a maior luta revolucionária de seu tempo, vinculando-a à luta de classes. Porém não podia antever que o fim da escravatura não libertou completamente os negros que, deixando a condição de escravos para entrar na condição assalariada, ainda tiveram de suportar praticamente mais um século de white supremacy amparada em leis e instituições discriminatórias. 
Não é nosso objetivo aqui reconstituir todo o debate que envolve distâncias e proximidades entre as duas correntes de pensamento (Bourdieu e Marx), nem se tem a pretensão de resolvê-lo; buscamos então retomá-lo em linhas gerais, para apontar as consequências do uso da noção de campo em Bourdieu e sua articulação com o conceito de exclusão, para pensar a função social da escola. Burawoy (2011, p. 37), um dos mais eminentes marxistas da atualidade, acredita que em parte Bourdieu desenvolveu as ideias de Marx, mas

[...] em um aspecto fundamental, Bourdieu também se desviou do marxismo na apropriação que fez do modelo dos campos baseado em $O$ Capital, em especial pela supressão da categoria exploração - que é tão central à análise marxista do capitalismo (...) Central também é a relação entre a exploração (relações de propriedade, de produção, de distribuição) e a própria produção (o processo de trabalho, a divisão do trabalho, as relações produtivas). A análise feita por Bourdieu dos campos sociais tende a colapsar essas duas relações, reduzindo a divisão do trabalho à simples posse de um capital e, com isto, eclipsando a ideia de exploração que, pelo menos no esquema marxiano, conduzia à luta de classes.

Em nossa análise concordamos que a construção da noção de campo e da distribuição das formas do capital retira a ênfase das relações de produção e da luta de classes; porém, não reduz a análise e a denúncia das relações de exploração, de injustiça, de desigualdades. Entre Bourdieu e Marx, a luta se opera em domínios muito distintos.

Não se constitui tarefa por demais exaustiva a busca da concepção de "grupo" na sociologia de Bourdieu. De entrada, pode-se notar que a noção em si, "grupo", não tem grande peso na arquitetura conceitual do autor. Em muitos trechos aparece como permutável com classes ou frações de classes (BOURDIEU, 1985); pode-se pensar em uma noção genérica de partição, ou seja, delimita partes da sociedade, ou partes de uma classe social, conjuntos de pessoas dotadas de algum atributo em comum; de modo geral, encontra-se embutido o adjetivo, assim: grupo social - elemento ou componente do sistema social.

A noção de grupo em Bourdieu pede um exame do conceito de "classe social". Buscando responder a questões sobre como os "grupos" se fazem e se desfazem, Bourdieu (2004, p. 94-95) tenta mostrar que os grupos existem tanto na realidade objetiva, quanto nas representações e em estratégias, visando modificar a realidade por meio da modificação de representações:

Assim, eu esperava mostrar que a lógica que eu havia apreendido a partir dos grupos
de base genealógica, famílias, clãs, tribos, etc., valia também para os agrupamentos
mais típicos de nossas sociedades, aqueles designados com o nome de classes. Assim
como as unidades teóricas que a análise genealógica recorta no papel não
correspondem automaticamente a unidades reais, práticas, do mesmo modo as classes
teóricas que a ciência sociológica recorta para explicar práticas não são
automaticamente classes mobilizadas. Em ambos os casos, estamos lidando com
grupos no papel...

Para Bourdieu (2004), as classes, como Marx as concebia, eram o resultado de uma ação política, ou mais exatamente, o "efeito de uma teoria". Neste sentido, as classes sociais 
“estão por fazer", não são dadas na realidade social. Ou seja, para que um aglomerado ou conjunto de indivíduos, partilhando as mesmas condições de vida, atue como classe, é necessário antes um trabalho de se tornar coletivo, agindo política e voluntariamente de modo coletivo. Deste modo, para se chegar à ação voluntária, um grupo deve desenvolver uma auto percepção (representação) como grupo ou classe e por meio da vontade política, põe em marcha a representação de um "grupo unificado".

Burawoy (2011) reforça que Bourdieu considerava perigosamente ilusória a tradição marxista que confundia a "classe no papel” com uma classe real, unificada, mobilizada, que só poderia existir como resultado de uma construção. $\mathrm{O}$ autor concorda com a crítica feita no sentido de que o marxismo não compreendeu adequadamente sua grande influência como "efeito teórico", ou seja, à medida que alguns representantes da classe trabalhadora incorporaram a visão (representação) que Marx criou da classe e realizaram uma coligação imaginária entre a "classe no papel" e a "classe mobilizada".

O que interessa, particularmente, é a vinculação explícita que Bourdieu (2004) faz do termo "grupo" ao poder simbólico e ao capital simbólico, afirmando que o "poder de fazer grupos" é a forma mais elaborada, por excelência, do poder simbólico, que, por sua vez está baseado em duas condições. A primeira delas é que o poder simbólico é fundado na posse de um capital simbólico. O capital simbólico é, na verdade, um efeito da distribuição das outras formas de capital em termos de reconhecimento ou de valor social, é poder atribuído aos que obtiveram reconhecimento suficiente para terem condições de impor o reconhecimento. A segunda condição é que a eficácia simbólica depende do tanto que uma visão defendida (um crédito, um reconhecimento, um valor) está, de fato, amparada na realidade; o capital simbólico é tanto mais eficaz, quanto mais ele esteja alicerçado na realidade objetiva.

Tirando-se do conjunto dessas afirmações e todas as suas implicações, chega-se, sem dúvida, ao fato que os grupos não somente são importantes porque dão gênese a agentes que atuam com vontade política "consciente" ou, ao menos voluntária, mas também porque dão gênese ao próprio capital simbólico, visto que o reconhecimento somente se obtém na interação entre indivíduos e grupos sociais, amparada no resultado de suas ações para a transformação da realidade objetiva. O valor social do reconhecimento é inerente aos grupos sociais. O "como" dessa operação requer que se estabeleça a natureza e a forma das "estruturas mentais" ou das formações simbólicas envolvidas, para se compreender o modo de interação. Nesse sentido, a postulação da representação social e dos processos de sugestão ou de influência social parece uma via frutífera para a compreensão do simbólico, pelos argumentos até aqui apontados.

$\mathrm{Na}$ sociologia das posições, o termo "grupo" aparece quase que em permanência, associado a uma "unidade simbólica". Embora não teorize isso de modo explícito, a ideia que os “grupos estão por fazer", que não são substâncias a priori da organização social, indica que a construção de uma unidade simbólica (partilha de crenças comuns) é dinâmica: manter, sustentar, expandir os grupos já estabelecidos; formar novos grupos que sustentem uma nova 
visão. O poder simbólico se funda no "poder de construir grupos" (BOURDIEU, 2004), que tem lastro em um trabalho incessante (dentro das lutas) de categorização, transformando o senso comum; " a formidable social power, the power to make groups by making the common sense, the explicit consensus, of the whole group". (BOURDIEU, 1985, p. 729).

Dentro dessa discussão sobre grupos de influência, o conceito de "campo social de lutas", proposto pelo autor, contribui para ampliar o olhar para a instituição escolar. Como afirma Boyer (2005, p. 272-273): "Por campo é preciso entender uma delimitação do mundo social, regida por leis e códigos próprios, quer se trate da universidade, quer do jornalismo, do mundo literário ou artístico, que formam tantos outros universos de convivência e de influência". Sobre esse assunto, seria conveniente atentar para algo que escreveu Castel (2005, p. 353) ao se referir à sociologia de Bourdieu: “[...] a sociedade faz-se, inicialmente, de coerções [...] o que importa para o sociólogo é o jogo com as coerções que estruturam o sentido das práticas". O autor levanta a hipótese de que Bourdieu, na verdade, não pretendeu elaborar uma "sociologia da reprodução", visto que sua ênfase foi propor uma "sociologia da ação", a qual revela intenção de superar a ordem das coerções, eventualmente tuteladas ou ocultadas.

Trata-se, portanto, de valorizar o espaço social constituído por "campos de lutas" que incluem relações simbólicas que funcionam em "mercados" com lógica específica. Nesse sentido, a sociologia dos bens simbólicos de Bourdieu suscita um olhar para a instituição escolar que privilegia crenças e suas relações com a geração de práticas. Em um primeiro momento, tais práticas poderiam ser associadas ao habitus. Porém, elas são mais abrangentes e demandam considerar, além de um habitus como aquisições e disposições dos agentes, os processos simbólicos coletivos de atribuição de significados e de valores. Essa ideia possibilita retomar o conceito bourdieusiano de "campo" em uma concepção de lutas materiais e simbólicas que ultrapassam a luta de classes em sua dimensão econômica.

O "campo" da escola, dessa maneira, se configura em lugar de produção e de reprodução de crenças que agem no mundo social e escolar. Ele se constitui em espaço para marcas de distinção, para julgamentos de agentes habilitados para estabelecer valores sobre "produtos escolares", muitas vezes prognosticando o que é obscuro para antecipar. O que, de fato, fundamenta o "campo escolar"? A princípio, uma relação de lutas envolvendo os quatro capitais (econômico, cultural, social e simbólico), as relações de gênero, e também, ampliandose essa perspectiva de Bourdieu, relações envolvendo tantas outras diferenças presentes na escola (por exemplo, étnicas, religiosas, deficiências físicas e mentais). Essas relações diversas supõem um processo social de lutas e de acumulação de capitais, particularmente o simbólico, desencadeado por valores atribuídos a objetos escolares por vários sujeitos, que sofrem efeito do campo ao qual pertencem. 


\section{CONCLUSÃO}

Com base na defesa de que é necessário ampliar a concepção econômica de "classe social" para compreender o espaço escolar, propõe-se, como continuidade das reflexões, o aprofundamento das interações grupais em articulação com posições no campo social, valorizando-se o espaço simbólico na negociação de representações e práticas. A relação entre grupos sociais e instituições permite aproximar os estudos de Bourdieu de uma abordagem psicossocial, por exemplo, a teoria moscoviciana das representações sociais. Tal aproximação possibilitaria investigar correspondências entre estrutura social e sistemas simbólicos, assim como a adesão de indivíduos e grupos a estes últimos, marcada pela posição ocupada no campo social.

Estudar sistemas representacionais nas interações grupais pode favorecer a compreensão de um conjunto de assimetrias posicionais que refletem as relações de poder que estruturam a sociedade e a escola. Vincular o termo "grupo" ao poder simbólico e ao capital simbólico na compreensão do "poder de fazer grupos" (BOURDIEU, 2004) pode ser uma pista para investigar divisões que ocorrem na escola que se quer "inclusiva". Para avançar reflexões sobre as trocas simbólicas na instituição escolar, que vão definindo sua função social, pode ser considerada a existência de um mecanismo não somente sociológico, mas também psicossocial. Buscando-se os fundamentos de crenças coletivas ou falta de conhecimentos coletivos, podem ser encontrados grupos que conferem valores a objetos escolares, reconhecendo-os e legitimando-os.

Essa presença de grupos que interagem no espaço escolar reforça o interesse de uma aproximação teórica entre a sociologia de Bourdieu e a perspectiva psicossocial da teoria moscoviciana das representações sociais. Pode-se tomar como ponto de partida, por exemplo, o modelo triádico proposto por Moscovici (1972), Ego-Alter-Objeto, que implica triangularidade entre o Ego (eu-grupo), o Alter (o Outro, as instituições, a cultura) e o objeto ao qual são atribuídos significados, valores. Os significados de objetos escolares, representados por diversos grupos que constituem a escola, seriam gerados nessa triangularidade em que os componentes se definem e se complementam. A tríade proposta é importante para a compreensão das interações grupais na construção de representações que expressam relações entre contextos sociais e grupos, entre ação individual/grupal e estrutura social, engendrando o modo como as pessoas de diferentes grupos representam objetos do cotidiano escolar, assim produzindo e/ou reproduzindo suas crenças.

Com esse desenho, o artigo procurou mostrar que, na busca pela escola da diversidade e heterogênea, a perspectiva do conceito de "classe social", fundada exclusivamente em uma visão essencialista do conflito social, derivando da divisão social do trabalho, mesmo que em uma perspectiva "histórica", é insuficiente para explicar a riqueza das interações sociais que ocorrem no cotidiano escolar, por causa, principalmente, da intensidade das trocas simbólicas presentes nesse espaço. Defende-se a necessidade de buscar um referencial teórico que 
explique melhor as relações sociais entre diversos agentes/grupos, contexto social e cultura escolar. O "campo escolar" seria assim produtor de valor como universo de crenças, entendendo-se que a crença no valor se reporta à presença de poder simbólico no espaço da escola. Como explica Michaud (2005, p. 286), "para Bourdieu, o poder simbólico não poderia residir no objeto, pois o valor que o constitui não passa de um efeito do campo", definindo-se "na própria estrutura do campo em que se produz e se reproduz a crença". O "campo" é, portanto, o exterior do objeto e produz seu valor. Nesta concepção, a dimensão material perde força sem a produção do valor. Aí está a fecundidade de uma aproximação entre a sociologia de Bourdieu e a perspectiva psicossocial da teoria moscoviciana das representações sociais para explicar as relações materiais e simbólicas que envolvem diferentes grupos na escola.

\section{REFERÊNCIAS}

BRASIL. Lei n. 13.005, de 25 de junho de 2014. Aprova o Plano Nacional de Educação e dá outras providências. Diário Oficial da União, Brasília, DF, Seção 1, Edição Extra.

BARRÉRE Anne; SEMBEL Nicolas. Sociologia da escola. São Paulo: Loyola, 2006.

BAUDELOT, Christian; ESTABLET, Roger. L'Ecole capitaliste em France. Paris: Librairie François Maspero, 1971.

BOURDIEU, Pierre. La distinction: Critique sociale du jugement. Paris: Minuit, 1979.

BOURDIEU, Pierre. The Social Space and the Genesis of Groups. Theory and society, California, Estados Unidos, v. 14, n. 6, p. 723-744. 1985. Disponível em: < http://goo.gl/uiMrwI>. Acesso em: 05 jul. 2015.

BOURDIEU, Pierre. La noblesse d'etat: Paris, Minuit, 1989.

BOURDIEU, Pierre. Raisons pratiques: Sur la théorie de l'action. Paris: Seuil, 1994.

BOURDIEU, Pierre. Coisas ditas. Tradução de Cássia Regina da Silveira e Denise Moreno Pegorim. São Paulo: Brasiliense, 2004.

BOURDIEU, Pierre. A dominação masculina. Tradução de Maria Helena Kühner. 11.ed. Rio de Janeiro: Bertrand Brasil, 2012.

BOURDIEU Pierre; PASSERON, Jean-Claude. La reproduction. Paris, Minuit: 1970.

BOYER, Robert. A arte do judoca. In: ENCREVÉ, Pierre; LAGRAVE, Rose-Marie.

Trabalhar com Bourdieu. Rio de Janeiro: Bertrand Brasil, 2005, p. 271-283.

BURAWOY, Michael. O marxismo encontra Bourdieu. Campinas, SP: Editora da UNICAMP, 2011. 
CASTEL, Robert. Les marginaux dans l'histoire. In. PAUGAM, Serge (Ed.) L'exclusion : l'état des savoirs. Paris: Éditions la Découverte, 1996, p.32-41.

CASTEL, Robert. Pierre Bourdieu e a rigidez do mundo. In: ENCREVÉ, Pierre; LAGRAVE, Rose-Marie. Trabalhar com Bourdieu. Rio de Janeiro: Bertrand Brasil, 2005, p.351-358.

DELARUE, Jean-Marie. La rélégation. Paris: Syros, 1991.

DEWEY, John. Democracia e educação: introdução à filosofia da educação. São Paulo: Companhia Editora Nacional, 1959.

DEWEY, John. Vida e educação. São Paulo: Melhoramentos, 1965.

DIAS, Fernando Correia. Durkheim e a Sociologia da Educação no Brasil. Em Aberto, Brasília, DF, v. 9, n. 46, p. 33-48. abr./jun.1990. Disponível em: 〈http://goo.gl/oJZYDl〉. Acesso em: 05 jul. 2015. ISSN 2176-6673.

DONZELOT, Jacques. Face à l'exclusion, le modèle français. Paris: Esprit. 1991.

DUBET, François. A escola e a exclusão. Cadernos de Pesquisa, São Paulo, SP, n. 119, p. 29-45. 2003. Disponível em: 〈http://goo.gl/M6UFWd>. Acesso em: 12 mar. 2015. ISSN $1980-5314$.

DURKHEIM, Emile. Sociologia e filosofia. Tradução de Fernando Dias Andrade. São Paulo: Ícone Editora, 2004.

FASSIN, Didier. Marginalidad et marginados, la cosntruction de la pauvreté urbaine en Amérique latine. In: PAUGAM, Serge (Ed.) L'exclusion. L'état des savoirs. Paris: Editions de la Découverte, 1996, p. 263-271.

GAZIER, Bernard. Implicites et incomplètes: les théories économiques de l'exclusion. In. PAUGAM, S. (Ed.) L'exclusion l'état des savoirs. Paris: Éditions la Découverte, 1996, p.42-51.

GIROUX, Henry. A Pedagogia radical e o intelectual transformador. In: GIROUX, Henry. Escola crítica e política cultural. 2.ed. São Paulo: Cortez: Autores Associados, 1988.

GRAMSCI, Antonio. Concepção dialética da história. São Paulo: Civilização Brasileira, 1989.

LENOIR, René. Les exclus: un français sur dix. Paris: Seuil, 1974.

LOSURDO, Domenico. A luta de classes: uma história política e filosófica. São Paulo: Boitempo Editorial, 2015.

MACEDO, Lino de. Ensaios pedagógicos: como construir uma escola para todos? Porto Alegre: Artmed, 2005. 
MARTINS, José de Souza. Exclusão social e a nova desigualdade. São Paulo: Paulus, 1997.

MARX, Karl. A luta de classes na França. São Paulo: Global. 1986.

MARX, Karl; ENGELS, Friedrich. Manifesto do Partido Comunista. Estudos Avançados, São Paulo, SP, vol. 12, n. 34, p. 7-46. 1998. Disponível em: < http://goo.gl/zLfqvu >. Acesso em: 05 jul. 2015. ISSN: 1806-9592.

MEKSENAS, Paulo. Sociologia da educação. Introdução ao estudo da escola no processo de transformação social. 15. ed. São Paulo: Loyola, 2011.

MICHAUD, Éric. Capitalização do tempo e realidade do carisma. In: ENCREVÉ, Pierre; LAGRAVE, Rose-Marie. Trabalhar com Bourdieu. Rio de Janeiro: Bertrand Brasil, 2005, p. 285-292.

MOSCOVICI, Serge. Society and Theory in Social Psychology. In: ISRAEL, J.; TAJFEL, H. (Eds.). The Context of Social Psychology. London and New York: Academic Press, 1972, p. $17-68$.

NOGUEIRA, Cláudio Marques Martins; NOGUEIRA, Maria Alice. A sociologia da educação de Pierre Bourdieu: limites e contribuições. Educação \& Sociedade, Campinas, SP, v. 23, n. 78, p. 15-35. abr. 2002. Disponível em: 〈 http://goo.gl/jGD9W>. Acesso em: 04 fev. 2015. ISSN: 1678-4626.

PARSONS, Talcott. O sistema das sociedades modernas. São Paulo: Pioneira, 1974.

PAUGAM, Serge. Introduction. In: PAUGAM, Serge. L'exclusion: l'état des savoirs. Paris: Editions la Découverte, 1996, p.7-19.

PISTRAK, Moisey Mikhaylovich. Fundamentos da escola do trabalho. São Paulo: Brasiliense. 1981.

SASSIER, Philippe. Du bon usage des pauvres: histoire d'un thème politique XVI-XX siècle. Paris: Fayard, 1990.

SNYDERS, Georges. Escola, classes e luta de classes. São Paulo: Centauro, 2005.

\section{Como citar este documento:}

LIMA, Rita de Cássia Pereira; CAMPOS, Pedro Humberto Faria. Classes sociais, campo, grupos: contribuições para pensar a função social da escola. ETD - Educação Temática Digital, Campinas, SP, v. 17, n. 3, set./dez. 2015. ISSN 1676-2592. Disponível em:

<http://periodicos.sbu.unicamp.br/ojs/index.php/etd/article/view/8638223>. Acesso em: 14 dez. 2015. 